\title{
Effect of Substrate Temperature on Structural and Optical Properties of CdO Thin Films
}

\author{
Hanan R. A. Ali \\ Department of Physics, College of Education, University of Tikrit, Tikrit, Iraq \\ E-mail address: hanantaleeb@yahoo.com
}

\begin{abstract}
Thin films of $\mathrm{CdO}$ have been prepared by spray pyrolysis technique. XRD analysis reveals that all the prepared samples were polycrystalline and have preferred orientation along [111] orientation. The surface topography was determined by AFM which indicate that surface roughness and rms roughness were increased by the increasing of substrate temperature. The optical energy gap were determined and its value lies between $(2.4-2.5) \mathrm{eV}$.
\end{abstract}

Keywords: cadmium oxide; spray pyrolysis technique; XRD; AFM; thin films; sol-gel

\section{INTRODUCTION}

$\mathrm{CdO}$ have been widely used as a transparent conducting oxide thin films due to its unique properties such as, high transmission coefficient in the visible range of the electromagnetic spectrum, high electrical conductivity. It has n-type semiconducting and an optical band gap lies between (2.2-2.7) eV depending on the kind of technique used and the preparation condition of that method used ${ }^{[1-3]}$. These properties make $\mathrm{CdO}$ thin films very useful for applications, such as heat mirror, solar cells, antireflection coatings, nonlinear optics and gas sensors ${ }^{[4-9]}$. CdO thin films have been prepared by several techniques such as, reactive sputtering, R F magnetron sputtering, sol-gel dip coatings, chemical bath deposition and chemical spray pyrolysis ${ }^{[10-15,20-24]}$. The aim of this work is to study the effect of substrate temperature on some structural and optical constants utilizing chemical spray pyrolysis.

\section{EXPERIMENTAL}

Cadmium oxide thin films were prepared by chemical spray pyrolysis technique, using a laboratory designed atomizer. A homogeneous solution was prepared by dissolving cadmium chloride of $0.1 \mathrm{M}$ in $100 \mathrm{ml}$ re -distilled water. The microscope glass substrate after subjected to the cleaning process were placed on the hot plate until it reaches the desired temperature (substrate temperature was taken at 350, 400 and $450{ }^{\circ} \mathrm{C}$ ). The rest of the conditions were kept constant such as flow rate $5 \mathrm{ml} / \mathrm{min}$, distance between the substrate and nozzle $29 \mathrm{~cm}$, carrier gas (air) $10^{5} \mathrm{~N} / \mathrm{cm}^{2}$, spraying time was $7 \mathrm{Sec}$ lasted for two minutes to avoid excessive cooling. XRD measurements were carried out by using XRD diffractometer type Philips PW 1850, $\mathrm{Cu} \mathrm{K} \mathrm{K}_{\alpha}$ target. Atomic force microscopy was performed using SPM 
AA3000 Angstrom Advanced Inc. USA. Optical measurements were recorded using Shimadzu UV-Vis double beam spectrophotometer in the wavelength range (300-900) $\mathrm{nm}$.

\section{RESULTS AND DISCUSSION}

The crystalline quality of the films with various substrate temperature was performed by XRD analysis. The observed peaks in Fig. 1 matches well with JCPDS No. 05-0640 of the CdO. All the films indicate a preferred orientation along (111) plane and the other two peaks (200) (220) are observed also.

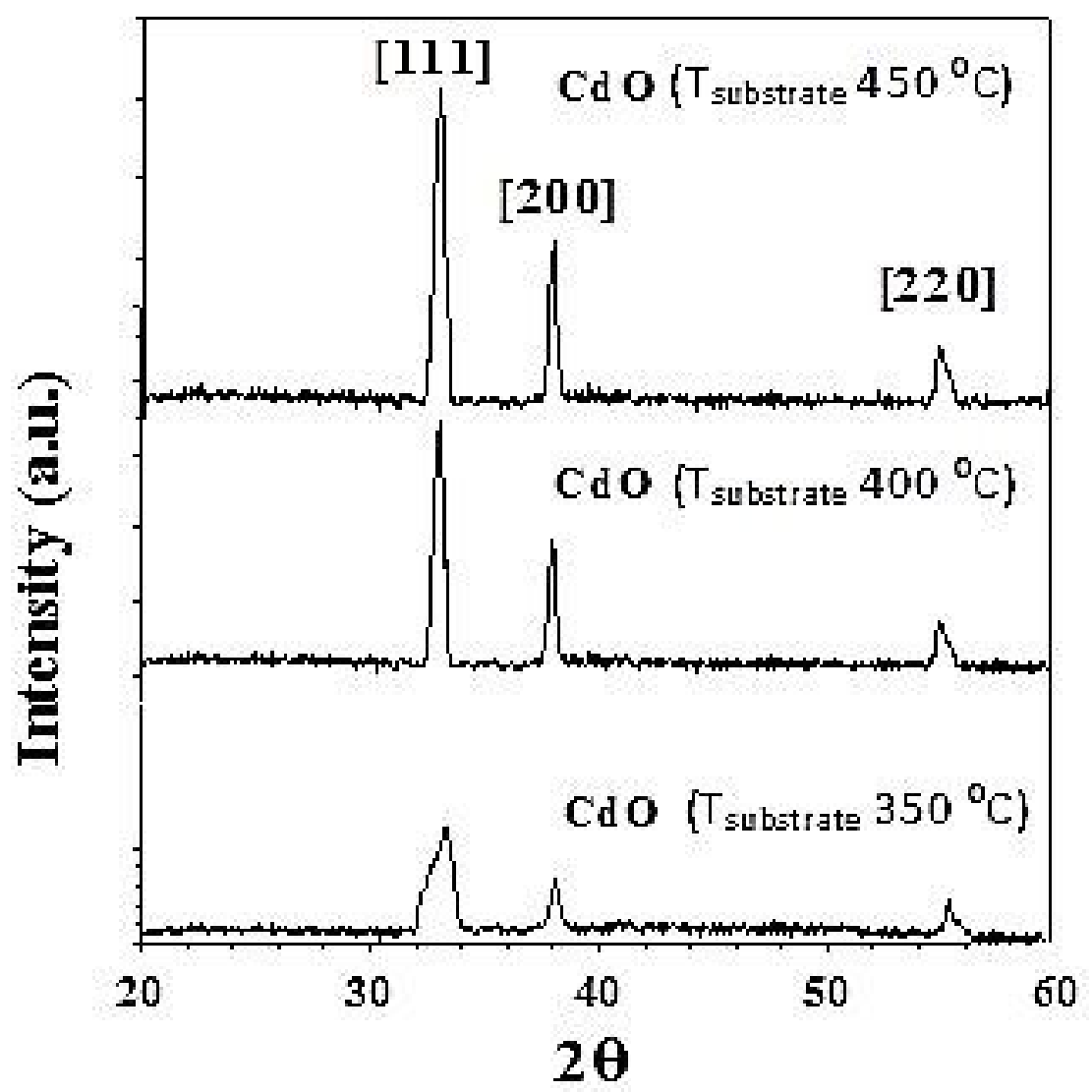

Fig. 1. XRD of $\mathrm{CdO}$ of different substrate temperature.

It was found that the intensity and the width of the peak depends on substrate temperature. The average crystallite size (D) was estimated from the full width at half maximum $(\beta)$ by applying Scherrer formula ${ }^{[16]}$ :

$$
D=\frac{0.9 \lambda}{\beta \cos \theta}
$$

where $\lambda$ is the x-ray wavelength, $\beta$ should be in radian and $\theta$ corresponds to the position peak.the results were summarized in Table (1). 
Table 1. Crystallite size, surface roughness and rms roughness of the deposited films of CdO.

\begin{tabular}{|c|c|c|c|}
\hline $\begin{array}{c}\text { Substrate } \\
\text { Temp. }{ }^{\circ} \mathrm{C}\end{array}$ & $\begin{array}{c}\text { Crystallite size } \\
\mathrm{nm}\end{array}$ & $\begin{array}{c}\text { Surface roughness } \\
\mathrm{nm}\end{array}$ & $\begin{array}{c}\text { rms roughness } \\
\mathrm{nm}\end{array}$ \\
\hline 350 & 11 & 5.94 & 18.5 \\
\hline 400 & 19 & 8.42 & 26.9 \\
\hline 450 & 37 & 14.2 & 33.8 \\
\hline
\end{tabular}

AFM images of the films prepared under various substrate temperature are shown in Fig. 2. For all the prepared films, an area of $(5 \mu \mathrm{m} \times 5 \mu \mathrm{m})$ has been used for evaluation, as can be seen from Table 1, the surface roughness and root mean square (rms) values were increased with the increasing of substrate temperature.

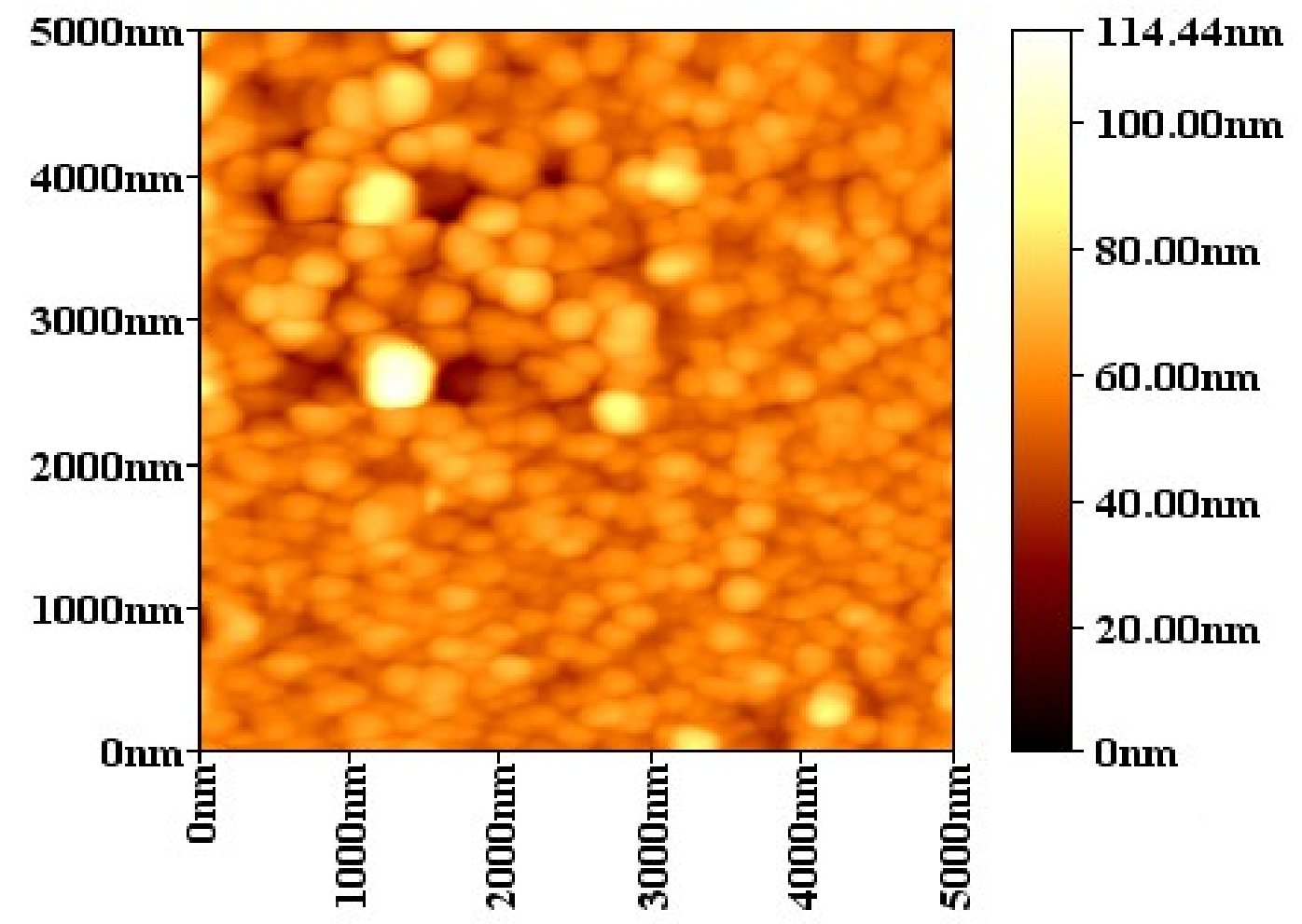




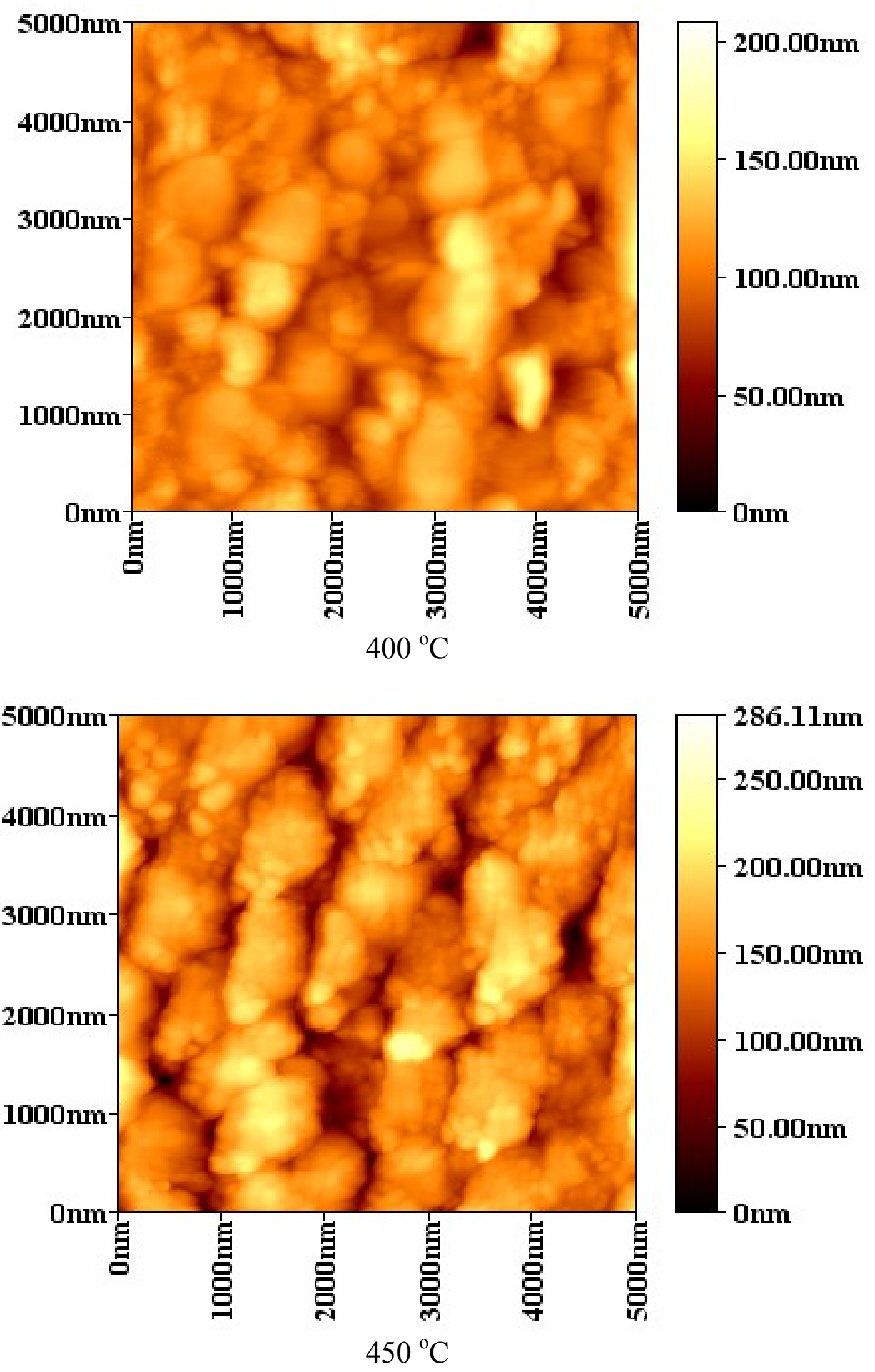

Fig. 2. AFM images for $\mathrm{CdO}$ thin films of different substrate temperature. 
The variations in optical transmittance of $\mathrm{CdO}$ thin films, deposited at various substrate temperature, are shown in Fig. 3. The transmittance of the films was influenced significantly by the substrate temperature. Transmittance decreased sharply below $550 \mathrm{~nm}$ which might be due the strong absorbance of the film within this region.

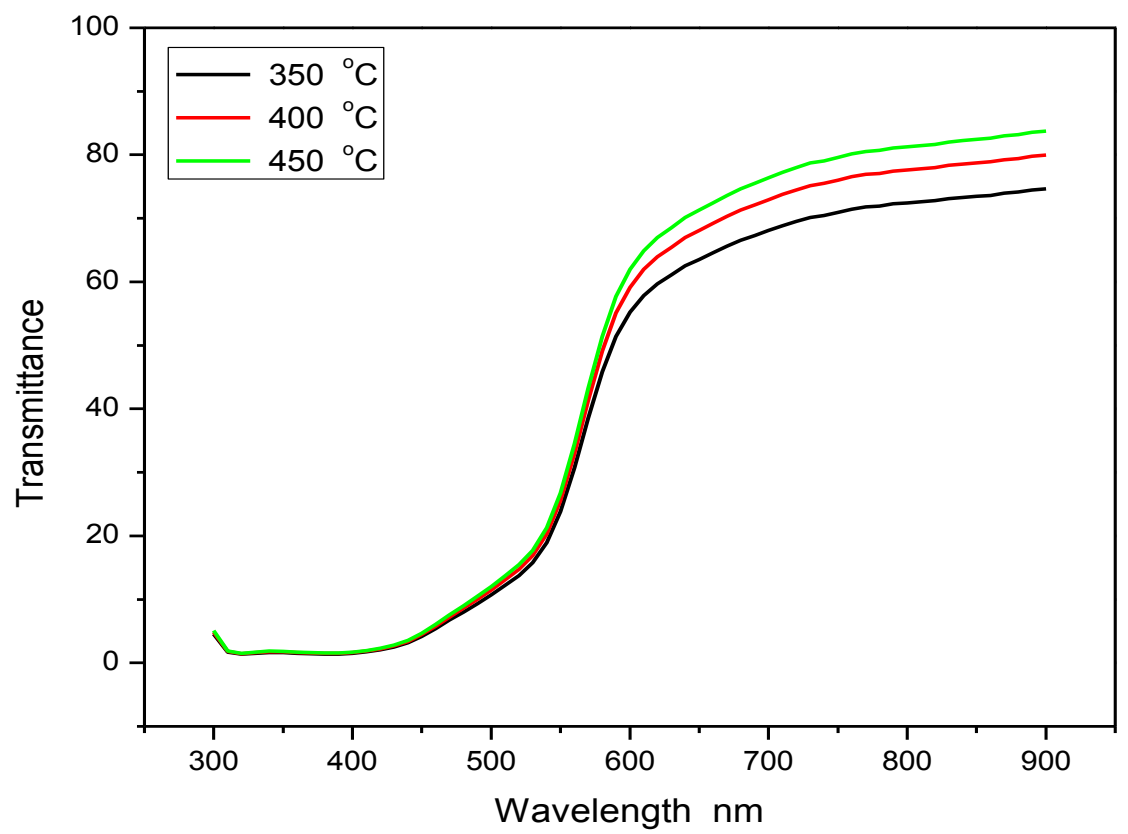

Fig. 3. Optical transmittance versus wavelength of different substrate temperature.

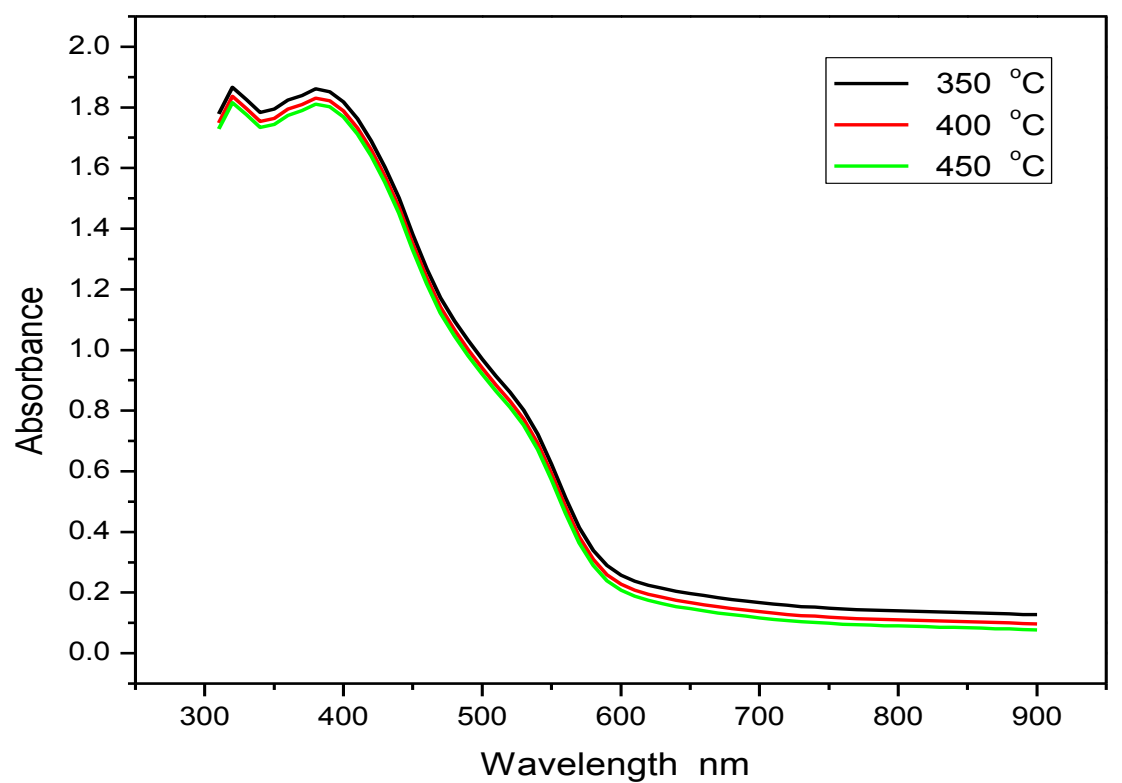

Fig. 4. Absorbance versus wavelength of different substrate temperature. 
The deposited films at lower substrate temperature has a less transmittance in the visible region in comparison with the films at higher substrate temperature. The increase in transmittance may be attributed to the increase in structural homogeneity and the crystallinity of the film with the increase in substrate temperature ${ }^{[17]}$. Fig. 4 shows the optical absorption spectra of $\mathrm{CdO}$ thin films at different substrate temperature. It is seen from the Fiqure that the maximum absorption occuurs near $320 \mathrm{~nm}$, showing another peak around $380 \mathrm{~nm}$, and start to decay exponentially in the visible region and, remain nearly constant after $620 \mathrm{~nm}$. The spectra reveal that the absorbance was decreased by the increase in substrate temperature.

The optical energy gap $E_{g}$ was estimated by assuming a direct transition between valence and conduction bands. Applying Tauc's relation which can be introduced by the following relation ${ }^{[19]}$ :

$$
\alpha h v=A\left(h v-E_{g}\right)^{1 / 2}
$$

where $A$ is constant, $\alpha$ the absorption coefficient, $h v$ the incident photon energy, $E_{g}$ is determined by extrapolating the straight line portion seen in Fig. 5 to $\alpha h v=0$, it can be observed from this Figure that the value of the optical band gap increases by doping from 2.4 $\mathrm{eV}$ to $2.5 \mathrm{eV}$. This increment may be due to the enhancement of crystallity order which can be clearly seen from the result of XRD and AFM.

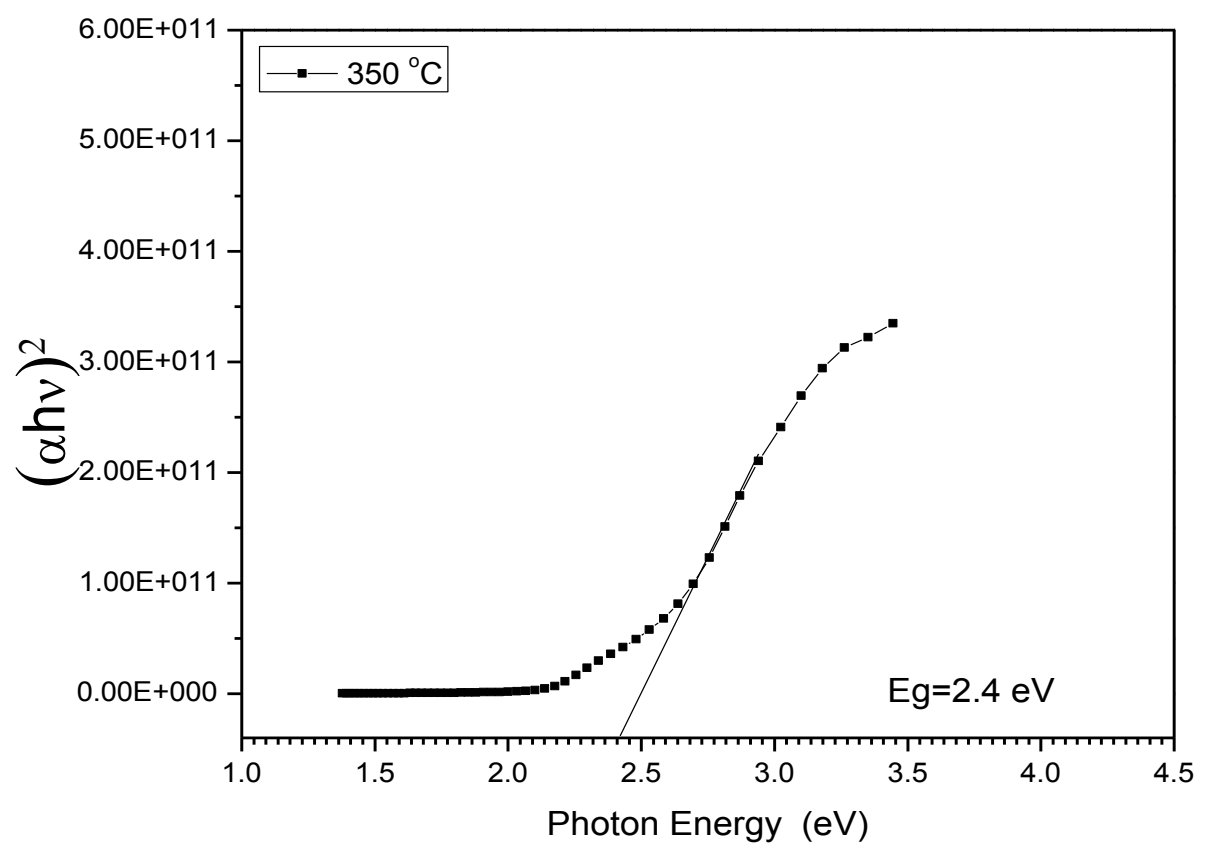

Fig. 5. $(\alpha h v)^{2}$ versus wavelength of different substrate temperature. 

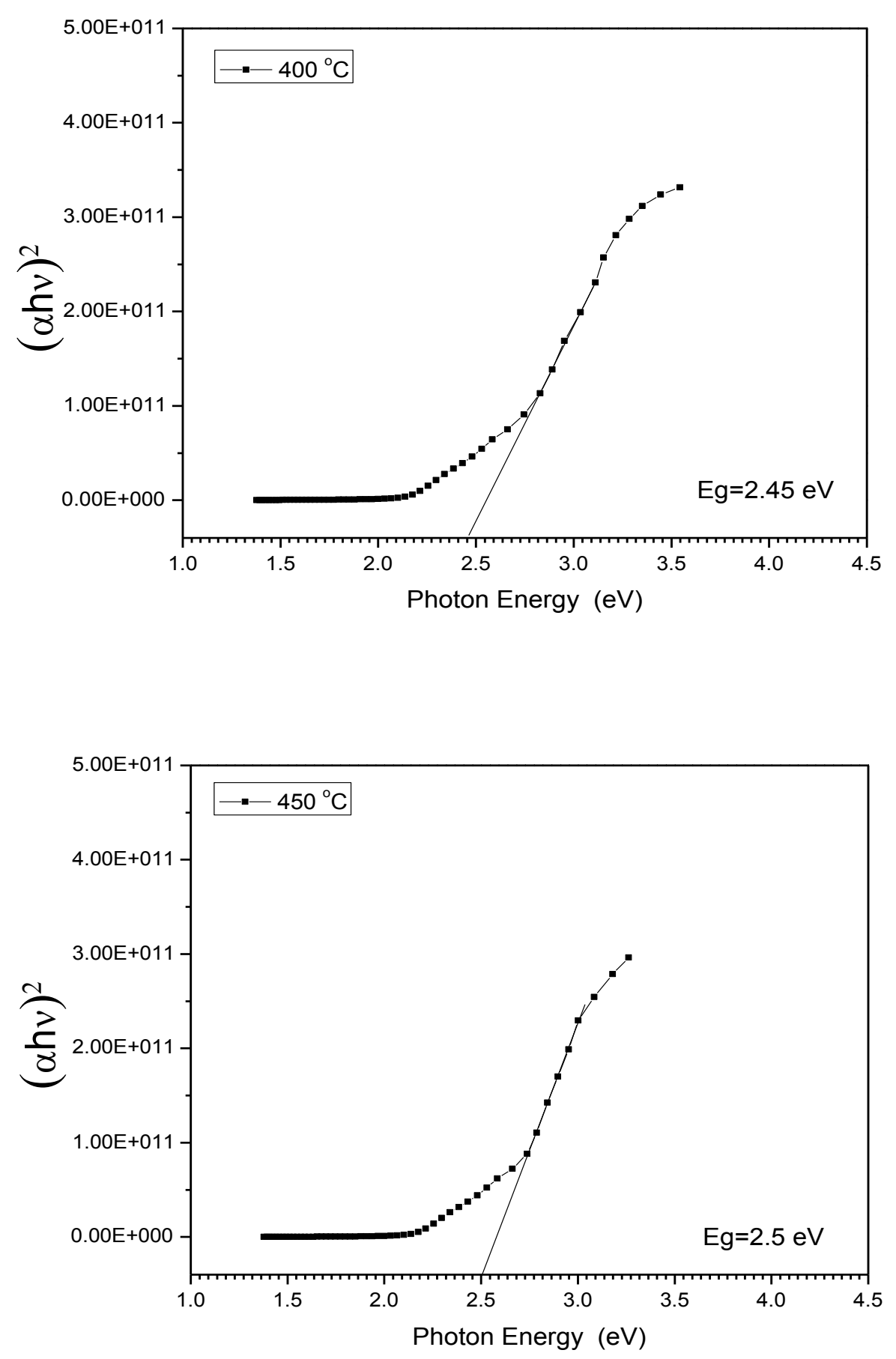

Fig. 5 (continue). $(\alpha h v)^{2}$ versus wavelength of different substrate temperature.

Fig. 6 shows the variation in the refractive index with wavelength, it was observed from the Fig. That the refractive index of the film decrease after $550 \mathrm{~nm}$ with the increase of substrate temperature. This decrease may be due to the larger grain size and lower strain in the film deposited at higher temperature ${ }^{[18] .}$ 


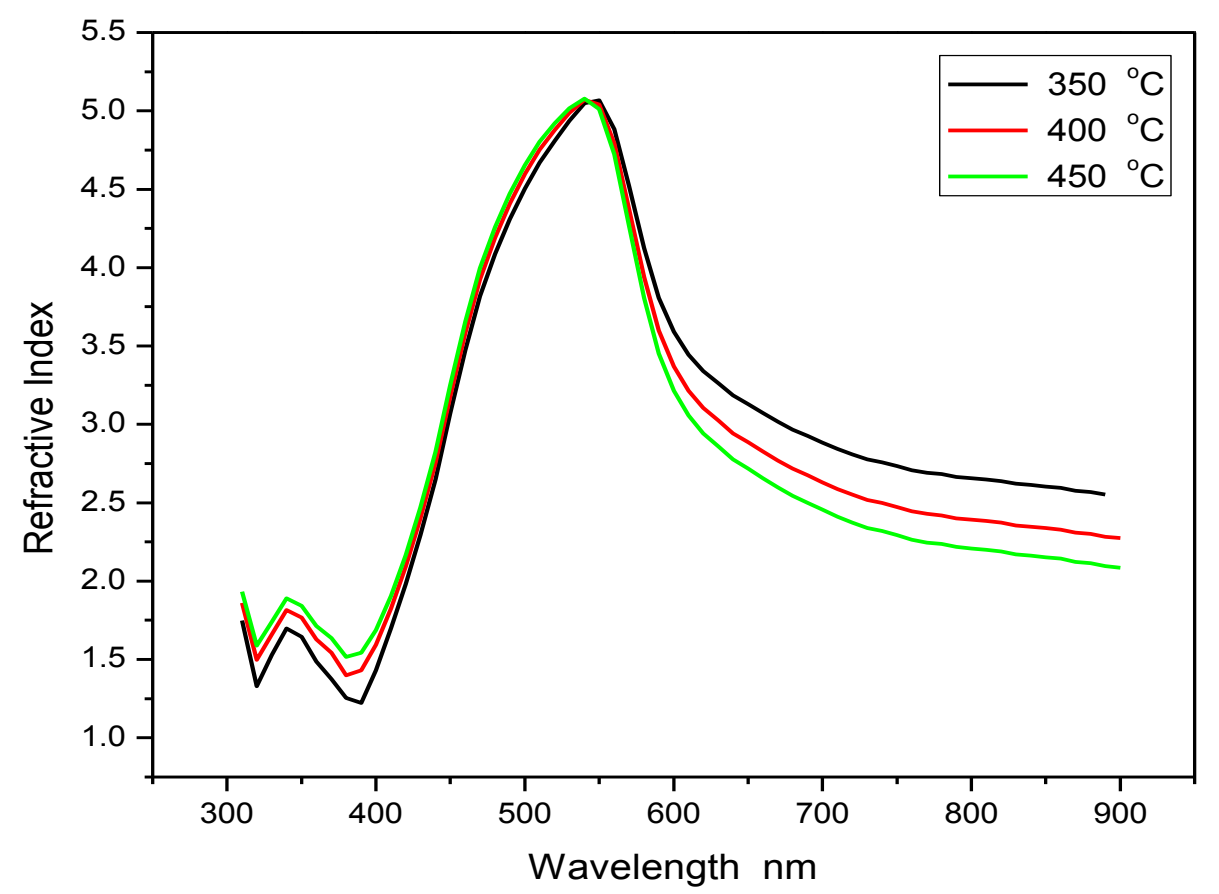

Fig. 6. Refractive index versus wavelength of different substrate temperature.

\section{CONCLUSIONS}

Cadmium oxide thin films have been successfully prepared by spray method. The effect of substrate temperature had been studying. The structure and optical properties were determined, XRD and AFM results were in coincidence, which concerned the increment of the grain size as the substrate temperature increased. The transmittance was increased by the increase in substrate temperature as well as the optical energy gap.

\section{Reference}

[1] R. S. Rusu, G. I. Rusu, J. Optoelctronics and Advanced Materials 7 (2005) 1511.

[2] A. A. Dakhel, J. Material Science 46 (2004) 6925.

[3] A. A. Dakhel, A. Y. Ali-Mohamed, J. Sol-Gel Sci. Technol. 44 (2007) 241.

[4] R. Maity, K. K. Chattopadhy, Sol. Energy Mater. Sol. Cells 90 (2006) 597.

[5] B. J. Lokhande, P. S. Patil, M. D. Uplane, Mater. Chem. Phys. 84 (2004) 238.

[6] K. Matsubara, P. Fons, K. Iwata, A. Yamada, K. Sakurai, H. Tampo, S. Niki, Thin Solid Films 341 (2008) 369.

[7] F. Z. Henori, A. A. Dakhel, Laser Phys. 18 (2008) 1557.

[8] R. R Salunkhe, D. S. Dhawala, P. P. Dunai, C. D. Lokhande, Sens. Actuators B 140 (2009) 86. 
[9] R. Srinivasaraghavan, R. Chandiramouli, B. G. Teyaprakosh, S. Seshadri, Spectrochimica Acta Part A: Molecular and Bio Molecular Spectroscopy 102 (2013) 242.

[10] N. Ueda, H. Maeda, H. Ozono, H. K. Awazoe, J. Appl. Phys. 84 (1998) 6174.

[11] Wei-Min Cho, Guan-Ru He, Ting-Hong Su, Yow-Jon Jin, Applied Surface Science 258 (2012) 4632.

[12] A. A. Ziabari, F. E. Ghodsi, G. Kiriakidis, Surface Coating Technology 213 (2012) 15.

[13] A. S. Kamble, R. C. Pawar, J. Y. Patil, S. S. Suryavanshi, P. S. Patil, J. Alloy Comp. 509 (2011) 1035.

[14] D. lanb, S. J. C. Irvine, J. Cryst. Growth 332 (2011) 17.

[15] V. Biligin, I. A kyuz, S. Kose, F. Atay, Semicond. Sci. Technol. 21 (2006) 579.

[16] E. F. Kaelble, Handbook of X-rays for diffraction,emission, absorption, and microscopy. McGraw-Hill, New York, (1967) p. 5.

[17] Sudjaatmoko, Wirjoadi, B. Siswanto, Atom Indonesia 35 (2009) 115.

[18] M. R. A. Bhyiyan, M. A. H. Miah, J. Begum, J. Bangladesh Academy of Science 36 (2012) 233.

[19] J. Tauc, Amorphous and Liquid Semiconductors, Plenum Press London, 1974.

[20] Nadir Fadhil Habubi, Sami Salmann Chiad, Saad Farhan Oboudi, Ziad Abdulahad Toma, International Letters of Chemistry, Physics and Astronomy 4 (2013) 1-8.

[21] Saad F. Oboudi, Nadir F. Habubi, Ghuson H. Mohamed, Sami S. Chiad, International Letters of Chemistry, Physics and Astronomy 8(1) (2013) 78-86.

[22] J. A. Najim, J. M. Rozaiq, International Letters of Chemistry, Physics and Astronomy 10(2) (2013) 137-150.

[23] Majid H. Hassouni, Khudheir A. Mishjil, Sami S. Chiad, Nadir F. Habubi, International Letters of Chemistry, Physics and Astronomy 11 (2013) 26-37.

[24] K. K. Patankar, International Letters of Chemistry, Physics and Astronomy 1 (2014) $1-8$. 